\title{
APLICAÇÃO DE GEOPROCESSAMENTO NO ZONEAMENTO DE ÁREAS DE INSTABILIDADE DA BACIA DO MANANCIAL DO RIO SANTO ANASTÁCIO/SP.
}

\author{
Stela Rosa Amaral Gonçalves ${ }^{1}$, Renata Ribeiro de Araújo ${ }^{2}$ \\ ${ }^{1}$ Curso de Engenharia Ambiental da Faculdade de Ciências e Tecnologia - UNESP- Presidente Prudente. ${ }^{2}$ Docente da \\ Faculdade de Ciências e Tecnologia - UNESP - Presidente Prudente. E-mail: stelarosaengenharia@gmail.com
}

\section{RESUMO}

O presente trabalho teve como objetivo a aplicação do geoprocessamento para elaboração de mapa síntese de zoneamento de áreas de instabilidade da bacia do manancial do rio Santo Anastácio/SP. Utilizou-se o software Spring (versão 5.2), uso e cobertura da terra, drenagem vetorizada na escala de 1:10000, imagens do Satélite Landsat e amostra de altimetria na escala de 1:50000. Criou-se um plano de informação correspondente a distancia à drenagem e também um de declividade. Realizou-se uma padronização Fuzzy dos planos de informações. Posteriormente com os Planos de informação, distância ao rio e declividade padronizados e o plano ponderado de uso e cobertura da terra pode-se utilizar o Processo AHP e Operador Fuzzy Gama para elaboração do mapa Síntese de instabilidade. Por fim, chegou-se a conclusão que o método AHP foi mais eficiente comparado ao resultado gerado pelo operador Fuzzy Gama devido a confusões geradas pelo operador.

Palavras-chave: Geoprocessamento. SIG. Zoneamento. Bacia Hidrográfica. Método AHP.

\section{INTRODUÇÃO}

O Zoneamento das áreas de instabilidade consiste na elaboração de um diagnóstico dos meios geo-biofísico e sócio-econômico, gerando um mapa síntese de Instabilidade Ambiental. Este é um instrumento de fundamental importância para o planejamento social, político e ambiental, bem como para tomada das principais decisões em inúmeros projetos, como expansão urbana.

São áreas instáveis aquelas que apresentam alguns potencial de degradação, ou seja, podem ser áreas mais próximas de lugares onde a própria dinâmica da natureza não é constante o que facilita a origem de processos erosivos ou de degradação ambiental.

Em uma bacia hidrografia seu comportamento hidrológico está em função de suas características morfológicas, dentre elas temos a cobertura vegetal, área, forma e topografia. Segundo Collischonn (2008); Tassi (2008), a utilização de SIG pode ser muito eficiente para representação de bacias hidrográficas detalhadamente e o tipo da vegetação, uso e cobertura do solo e tipo do solo são características que influenciam diretamente na formação do escoamento superficial e evapotranspiração.

Desta forma este trabalho teve o objetivo por meio de um SIG buscou-se zonear o manancial do rio Santo Anastácio, no município de Presidente Prudente/SP, em função de sua 
instabilidade que poderá ser Muito Alta, Alta, Média, Baixa e Muito Baixa bem como também comparar os métodos AHP e operador Gama escolhidos para geração do mapa síntese.

\section{METODOLOGIA}

A área de estudo compreendeu as nascentes do rio Santo Anastácio totalizando uma área de 198,30 km². Esta área se localiza na Unidade de Gerenciamento de Recursos Hídricos do Pontal do Paranapanema - UGRHI-22, no Oeste Paulista, abrangendo parte dos municípios de Presidente Prudente, Pirapozinho, Regente Feijó, Anhumas e Álvares Machado. Está localizada entre as

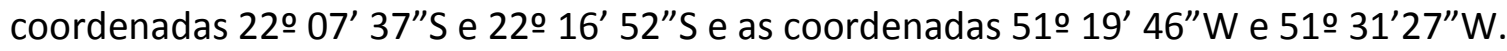

Para a execução do trabalho, utilizou-se o software Spring 5.2, software de sistema de informações geográficas (SIG) desenvolvido pela Divisão de Processamento de Imagens (DPI) do INPE, imagens Landsat do sensor TM do dia 01/09/2011 das Bandas 3,4 e 5, Shapefile de uma amostra de altimetria na escala de 1:50.000 e Arquivo Shapefile contendo a drenagem vetorizada a partir de Carta do IGC na escala de 1:10.000.

Primeiramente para elaboração do mapa de uso e cobertura da terra foram utilizadas imagens do Satélite Landsat5 (órbita/ponto - 222/075) do mês 09/2011, esse dado orbital adquiriu-se no site do INPE e os mesmos processados no software SPRING (5.2).

Após a escolha das imagens abriu-se uma primeira banda no Impima, um aplicativo que vem incorporado no Spring nesta versão 5.2, e recortou-se uma área de interesse da imagem exatamente do mesmo tamanho nas três bandas espectrais banda por banda. As três imagens importadas para Spring deram origem ao tamanho do projeto e registrou-se através da opção registro, sendo as coordenadas dos pontos de controle inseridas por meio do teclado.

Elaborou-se a melhor composição colorida sendo para Banda 3 o azul a Banda 4 o verde e Banda 5 o vermelho depois através da opção transformação RGB->IHS foram geradas as 3 imagens separadas de intensidade, matiz e saturação.

Posteriormente aplicou-se um contraste linear normal no histograma da imagem que representava a componente da cor chamada de intensidade e salvou-se esta imagem contrastada para ser utilizada juntamente com a componente de saturação e matiz na transformação IHS$>$ RGB.

Com a segmentação pode-se iniciar a classificação da imagem escolhendo as amostras de treinamento para que o Spring possa gerar uma imagem classificada nas classes temáticas de uso e cobertura chamadas de vegetação, culturas, água, área urbana, pastagem e solo exposto. Com a 
categoria de uso e cobertura pronta foi aplicada uma ponderação com auxilio de programação legal que gerou outro modelo numérico e plano de informação contendo a declividade ponderada.

Considerou-se que a classe água seria de alta instabilidade e por isso receberia o valor 1, a classe vegetação por si tratar principalmente de mata ciliar recebeu o valor 0,8 , solo exposto recebeu 0,6 , pastagem 0,4 , culturas 0,2 e área urbana recebeu o valor 0,1 e não o valor 0 porque como se trata de um manancial considerou-se que não existem áreas estáveis apenas áreas com muito baixa instabilidade.

O mapa de declividade foi elaborado a partir de um Shape de Amostra na escala de 1:50000 onde primeiramente com a amostra gerou-se uma grade regular utilizando o interpolador Média Ponderada Por Quadrante e em seguida selecionou-se a grade gerada da interpolação como componente de entrada e a unidade escolhida foi a porcentagem pois a legislação ambiental aborda esse atributo ambiental como porcentagem e não em graus.

Desta forma de acordo com a Lei 12.651 de 25 de maio de 2012 no seu capitulo II artigo quarto temos que: "Considera-se Área de Preservação Permanente, em zonas rurais ou urbanas, para os efeitos desta Lei: as encostas ou partes destas com declividade superior a $45^{\circ}$, equivalente a $100 \%$ (cem por cento) na linha de maior declive".

Depois de feito a declividade aplicou-se a lógica fuzzy onde se padroniza o plano de informação em valores entre 0 e 1 por meio de uma função sigmóide onde valores a baixo de $2 \%$ são classificados como zero e valores a cima de $15 \%$ são classificados como 1 considerando o zero como áreas com baixa instabilidade e o um como áreas de alta instabilidade. Feito a padronização da função do Excel criou-se outro modelo numérico e PI com a declividade padronizada com ajuda de programação legal.

O mapa de distancia ao rio foi elaborado a partir de um uma drenagem na escala de 1:10000 da área de estudo onde primeiro criou-se 2 classes, uma que continha o Rio Santo Anastácio e seus afluentes e outra que continha o reservatório da área de manancial. Tendo as classes criadas por meio do menu temático na opção mapa de distancia foi possível criar um plano contendo uma grade e uma imagem que representavam a distancia aos rios que compunham a drenagem.

O próximo passo, portanto foi outra padronização utilizando lógica Fuzzy por meio da linguagem Legal onde os valores da distancia foram padronizados entre 0 e 1 lembrando que antes da programação como também foi aplicado uma função sigmoidal houve a necessidade de verificar no Excel onde valores menores que 30 metros recebem o numero 1 sendo áreas de alta 
instabilidade e valores menores que 50 metros recebem o zero classificados como valores de baixa instabilidade.

Posteriormente com os Planos de informação distancia ao rio e declividade padronizados e o um plano ponderado de uso e cobertura da terra pode-se utilizar o Método AHP (Processo Analítico Hierárquico) onde com auxilio da opção Suporte à decisão AHP do Spring pode-se atribuir pesos aos planos padronizados e de posse desses pesos o próprio programa calcula a razão de consistência da matriz que deve ser menor do que 0,1 para ser considerada uma matriz consistente e desta forma elaborar o mapa síntese.

Para este mapeamento utilizou-se que o plano da distancia ao rio padronizada era um pouco melhor do que a declividade padronizada e melhor do que o uso e ocupação ponderado. Já o plano da declividade padronizado era algo melhor do que o plano de uso e cobertura ponderado.

O método Fuzzy Gama foi aplicado por meio de uma função matemática que levou em consideração o produto de uma soma algébrica com o produto algébrico. A soma algébrica foi elevada a um fator gama 0.6 e o produto algébrico foi elevado a um valor gama 0,4. Operador Fuzzy Gama para elaboração do mapa Síntese foi aplicado por meio de declarações, instanciações e sua respectiva operação matemática na programação legal. Ao fim com uma ferramenta de calculo de medida de classe do Spring foi possível obter os valores em quilômetros quadrados respectivos de cada classe para os dois métodos.

\section{RESULTADOS}

O plano de informação temático uso e cobertura da terra e suas classes temáticas gerado está apresentado na figura 1. 


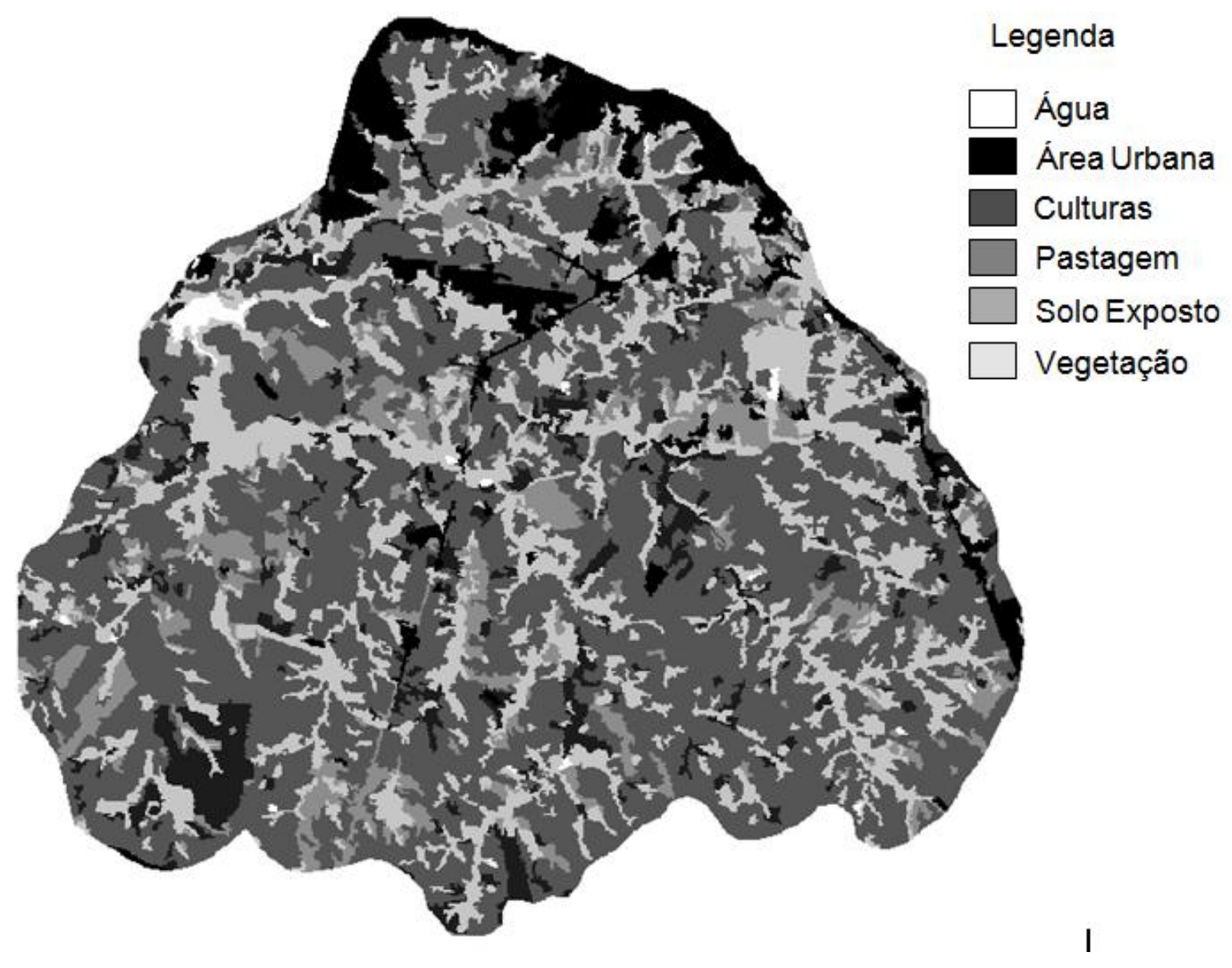

Figura 1. Representação do Plano de Informação "uso e cobertura da terra" e suas classes temáticas

Os resultados obtidos referentes a porcentagem e ao $\mathrm{Km}^{2}$ das áreas de cada classe do mapa de uso e cobertura estão apresentados na tabela 1.

Tabela 1. Cálculo de áreas em $\mathrm{Km}^{2} \mathrm{e} \%$ dos tipos de uso e ocupação da Bacia

\begin{tabular}{l|c|c}
\hline \multicolumn{1}{c|}{ Classes } & Área em \% & Área em $\mathbf{~ m}^{\mathbf{2}}$ \\
\hline Pastagem & 52,8 & 104,71 \\
\hline Vegetação & 22,87 & 45,36 \\
\hline Solo Exposto & 9,26 & 18,37 \\
\hline Área Urbana & 7,53 & 14,93 \\
\hline Culturas & 7,15 & 14,18 \\
\hline Água & 0,39 & 0,77 \\
\hline
\end{tabular}

O resultado do zoneamento com o método AHP está apresentado na figura 2 com uma razão de consistência de 0.003 . 


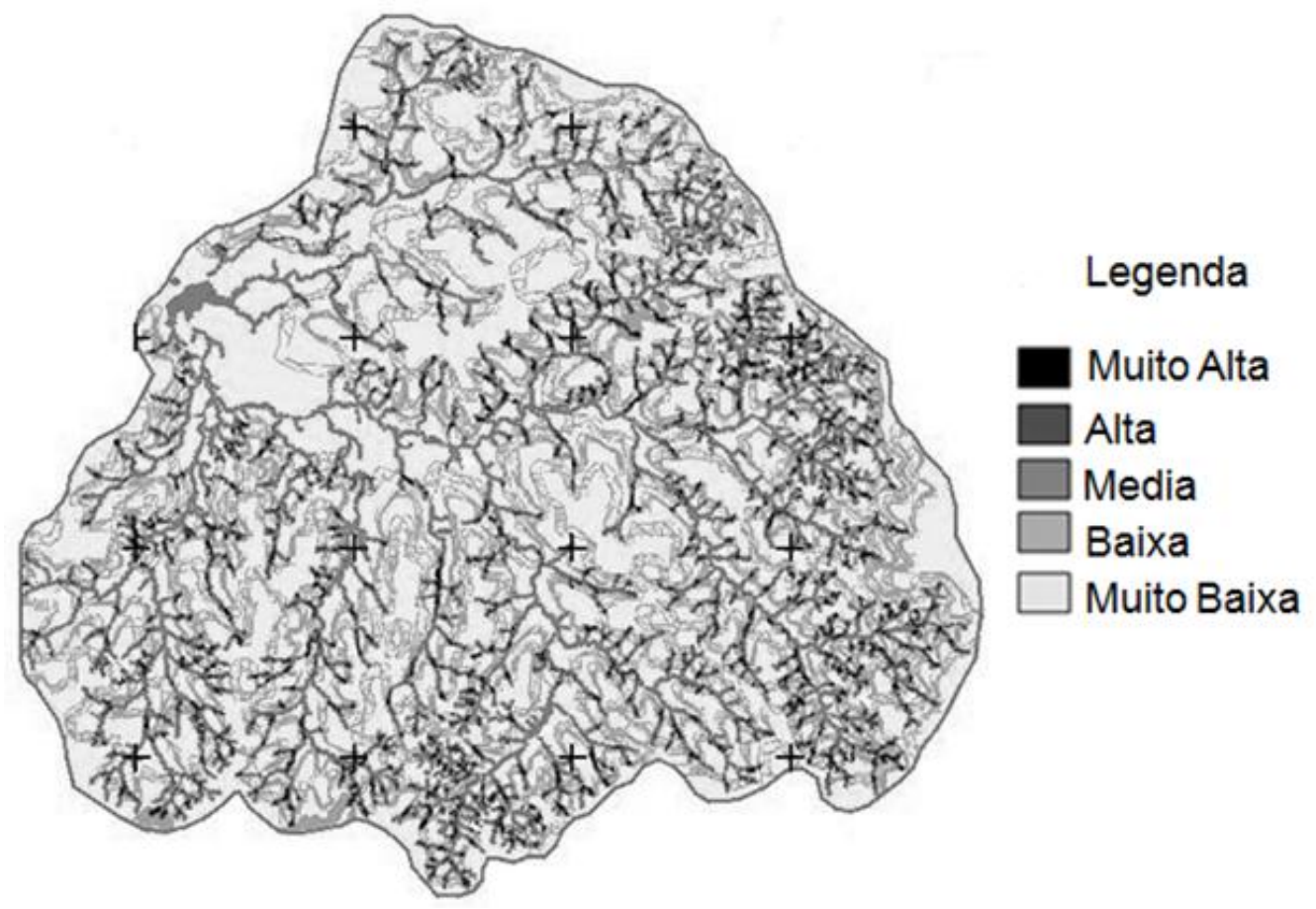

Figura 2. Zoneamento das áreas de Instabilidade da Bacia do Manancial do Rio Santo Anastácio gerado pelo método AHP.

O plano de informação temático resultante da aplicação do Operador Gama Fuzzy chamado de Zoneamento está apresentado na figura 3.

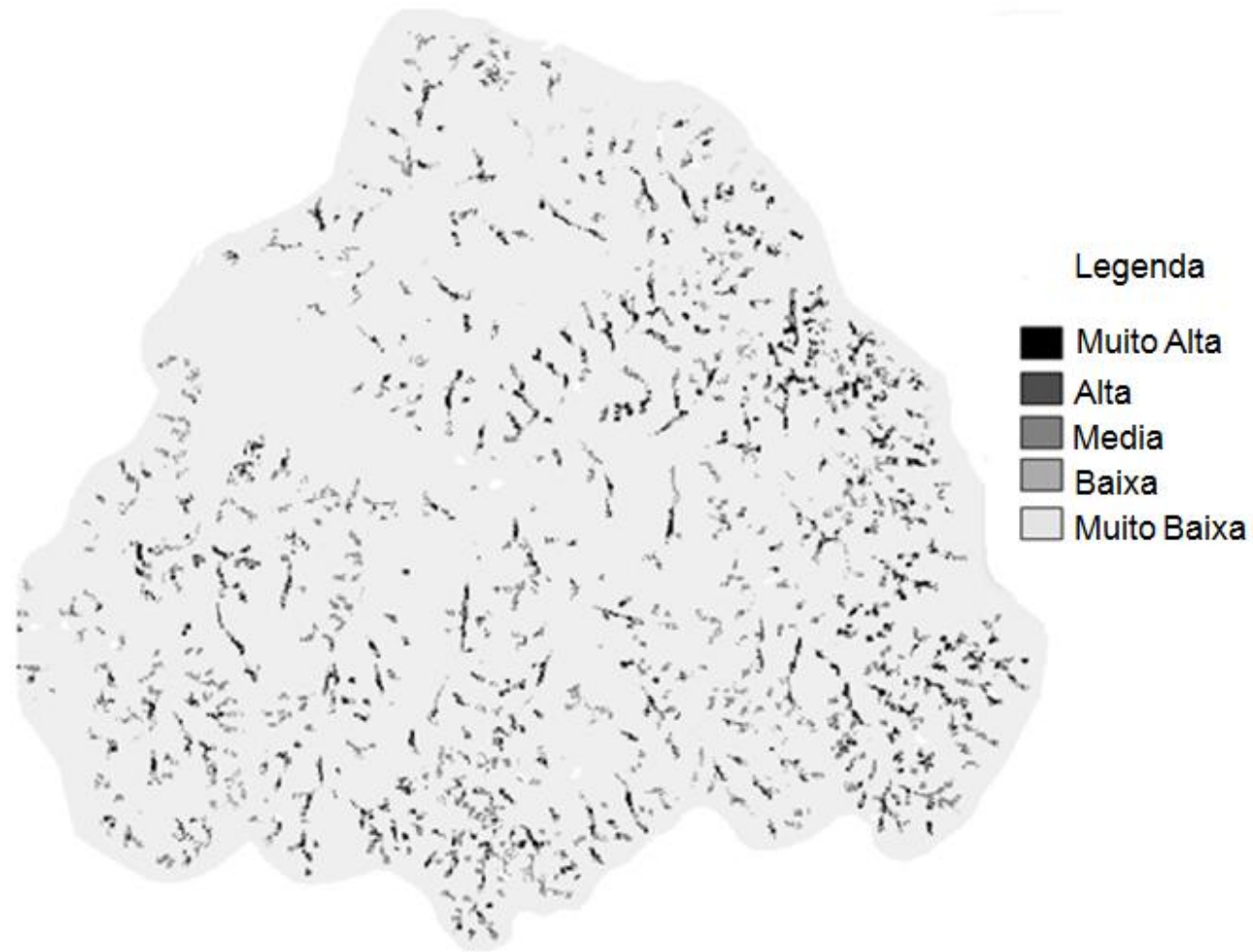

Figura 3. Zoneamento por meio do operador Fuzzy Gama. 
Com o mapa síntese de zoneamento elaborado pelos dois métodos foi calculado em $\mathrm{Km}^{2}$ as respectivas áreas de instabilidade de cada classe conforme resultado da tabela 2.

Tabela 2. Valores das áreas de Instabilidade Ambiental pelo método AHP e fuzzy gama.

Áreas de Instabilidade Ambiental

\begin{tabular}{c|r|r}
\hline Grau & \multicolumn{2}{|c}{$\mathbf{K m}^{\mathbf{2}}$} \\
\hline Método & \multicolumn{1}{|c}{ AHP } & \multicolumn{1}{c}{ Fuzzy Gama } \\
\hline Muito Alta & 9,94 & 3.88 \\
\hline Alta & 27,36 & 5,55 \\
\hline Média & 49,68 & 5,1 \\
\hline Baixa & 17,57 & 5,84 \\
\hline Muito Baixa & 93,78 & 117,94 \\
\hline Não classificado & 0,01 & 63,91 \\
\hline Total & 198,34 & 198,34 \\
\hline
\end{tabular}

\section{DISCUSSÃO}

A Razão de Consistência no método AHP foi satisfatória. Em relação aos critérios no suporte a decisão AHP considerou-se a distância ao rio padronizada um pouco melhor que a declividade padronizada isso porque as duas informações são importantes porém a distância ao rio é fator mais limitante em relação a áreas de instabilidade levando em consideração a sazonalidade da drenagem. Outro critério foi que a declividade padronizada é algo melhor que os valores de ponderação do uso e cobertura da terra isso foi adotado, pois independente de sua cobertura a legislação restringe das áreas de preservação permanente.

$\mathrm{Na}$ figura 3 observou-se claramente que o operador fuzzy gama é mais generalista em relação as diferentes zonas isso porque ouve um predomínio de classes de muito baixa instabilidade comprovado em seguida pela mensuração das classes por meio da tabela 1,além de deixar de classificar $62,91 \mathrm{~km}^{2}$ do total da área sendo uma parte significante do mapa síntese.

É importante também destacar que a represa na figura 3 foi classificada como área de muito baixa instabilidade o que não é verdade porque esses ambientes aquáticos sofrem muita variação principalmente com a sazonalidade das épocas de cheia e seca além de estarem nas áreas mais baixas da bacia recebendo o fluxo de todos os outros canais e consequentemente também são influenciados pelas alterações dos usos dos afluentes. O método AHP apresentou um resultado mais congruente com a realidade classificando as áreas bem próximas as nascentes com declividades mais acentuadas como áreas de muito alta instabilidade, outras áreas bem próximas ou dentro da área de preservação permanente como alta, como baixas e muito baixas as áreas 
mais longe da drenagem com uso e cobertura do solo composto principalmente por pastagem e área urbana e por fim as áreas de média instabilidade sendo de transição entre as altas e baixas e que tem um uso e cobertura que podem comprometer a conservação do solo como, por exemplo, o solo exposto e culturas.

Haja vista e o AHP conseguiu classificar praticamente toda a área de acordo com a tabela 1 e também apresentou um predomínio de pastagem na bacia em estudo que condiz com a realidade comprovada em trabalho de campo.

\section{CONCLUSÃO}

O geoprocessamento é uma ferramenta importante para representação da realidade e chegou-se a conclusão que o melhor método para geração do mapa de zoneamento das áreas de instabilidade é o método AHP. Conclui-se também que a partir desse mapa de instabilidade se tem condições de propor tomadas de decisões a fim de preservar a área de manancial estudada.

\section{REFERÊNCIAS}

BRASIL. Lei $\mathbf{1 2 . 6 5 1}$ de $\mathbf{2 5}$ de maio de 2012. Dispõe sobre a proteção da vegetação nativa; altera as Leis $\mathrm{n}^{\text {os }}$ 6.938, de 31 de agosto de 1981, 9.393, de 19 de dezembro de 1996, e 11.428, de 22 de dezembro de 2006; revoga as Leis nos 4.771, de 15 de setembro de 1965, e 7.754, de 14 de abril de 1989, e a Medida Provisória no 2.166-67, de 24 de agosto de 2001; e dá outras providências. Brasília, 25 de maio de 2012; $191^{\circ}$ da Independência e $124^{\circ}$ da República.

COLLISCHONN, W. ; TASSI, R. Introduzindo Hidrologia. Rio Grande do Sul. UFRGS, 2008.

MOREIRA, F. R. Inferência geográfica e suporte à decisão. In: CÂMARA, G. et al. Introdução à Ciência da Geoinformação. Cap. 9. Disponível em: <http://www.dpi.inpe.br/gilberto/livro/intro/>. 